\title{
Pain Assessment of Elderly Patients with Cognitive Impairment in the Emergency Department: Implications for Pain Management-A Narrative Review of Current Practices
}

\author{
Joshua Jones, Tin Fei Sim and Jeff Hughes * \\ School of Pharmacy, Curtin University, Western Australia 6102, Australia; \\ Joshua.S.Jones@student.curtin.edu.au (J.J.); T.Sim@curtin.edu.au (T.F.S.) \\ * Correspondence: J.D.Hughes@curtin.edu.au \\ Academic Editor: David Wright \\ Received: 9 March 2017; Accepted: 26 May 2017; Published: 1 June 2017
}

\begin{abstract}
Elderly people are susceptible to both falls and cognitive impairment making them a particularly vulnerable group of patients when it comes to pain assessment and management in the emergency department (ED). Pain assessment is often difficult in patients who present to the ED with a cognitive impairment as they are frequently unable to self-report their level of pain, which can have a negative impact on pain management. This paper aims to review how cognitive impairment influences pain assessment in elderly adults who present to the ED with an injury due to a fall. A literature search of EMBASE, ProQuest, PubMed, Science Direct, SciFinder and the Curtin University Library database was conducted using keyword searches to generate lists of articles which were then screened for relevance by title and then abstract to give a final list of articles for full-text review. Further articles were identified by snowballing from the reference lists of the full-text articles. The literature reports that ED staff commonly use visual or verbal analogue scales to assess pain, but resort to their own intuition or physiological parameters rather than using standardised observational pain assessment tools when self-report of pain is not attainable due to cognitive impairment. While studies have found that the use of pain assessment tools improves the recognition and management of pain, pain scores are often not recorded for elderly patients with a cognitive impairment in the ED, leading to poorer pain management in this patient group in terms of time to analgesic administration and the use of strong opioids. All healthcare professionals involved in the care of such patients, including pharmacists, need to be aware of this and strive to ensure analgesic use is guided by appropriate and accurate pain assessment in the ED.
\end{abstract}

Keywords: pain assessment; cognitive impairment; emergency department; elderly; falls; analgesic; quality use of medicines

\section{Introduction}

Pain assessment is the cornerstone of appropriate use of analgesics and the management of pain. It involves screening patients for pain, using an appropriate and validated assessment tool to assign a score that describes the severity and sometimes the nature of the pain, and then using the score in conjunction with guidelines, such as the World Health Organization analgesic ladder, to determine a suitable pain intervention for the patient [1,2]. Following the initial assessment, further periodic pain assessments are key in monitoring the efficacy of the chosen therapy and guiding dose adjustments and changes in pharmacotherapy to ensure that the patient is comfortable and that medicines are used appropriately [1]. As pharmacists are tasked with the responsibility of ensuring that patients achieve the best possible outcomes from their drug therapy, whilst at the same time ensuring quality use of 
medicines, they have a vested interest in confirming that pain assessments are timely and accurate. No more so than in vulnerable populations such as the elderly with cognitive impairment which limits their ability to self-report pain [3-7]. In such cases, pain often goes under-detected and under-managed despite patients having conditions/injuries known to cause pain, for example falls and fractures.

Injuries due to falls are a significant cause of morbidity and mortality worldwide [8]. Each year, approximately $28-35 \%$ of elderly adults (65 years of age and over) will experience a fall [9]. Falls contribute a significant economic burden for healthcare systems $[9,10]$ and place sufferers at risk of disability, loss of function and reduced quality of life [8,11]. In elderly adults, injuries to the hip and thigh are the most common injury sustained from a fall, about $27 \%$ of all injuries, followed by injuries to the head (20.5\%) [12]. About one in five injuries involve a fracture, with fractures to the neck of the femur accounting for $74 \%$ of the injuries to the hip or thigh [12].

Fractures are inherently painful and have been associated with an increased risk of developing an acute cognitive impairment such as delirium during a medical admission [13]. Furthermore, pain is associated with the development of delirium for patients admitted to hospital [14,15]. As cognitive impairment already increases the risk of injury due to a fall almost three-fold [16], as well as the risk of developing delirium during an admission $[13,17,18]$, elderly patients presenting with falls often have a co-existing cognitive impairment. The presence of a neurocognitive disorder such as dementia is reported to be present in 10-30\% of elderly patients in the emergency department (ED) $[17,19,20]$. This poses issues to their pain management if they are unable to self-report that they are in pain.

A regular and consistent approach to pain assessment is recognised as an important aspect of patient care as it informs and guides the management of pain and evaluation of the efficacy of pain interventions [21,22]. Self-report of pain is the preferred method of assessment, however this often becomes unattainable in elderly patients with cognitive impairment due to difficulties in comprehending commonly used pain assessment tools [3-7]. For example, a study by Lukas et al. [4] found that while the numerical rating scale (NRS) could be used by $75 \%$ of elderly adults with mild cognitive impairment to report pain, only $57 \%$ of patients with a moderate impairment and none of the severely impaired patients could utilise the tool. For patients with a cognitive impairment, alternative pain assessment methods, such as the observational and behavioural scales, may be more effective for assessing pain [22]. However, the extent of utilisation of such tools in the ED may be reduced due to challenges unique to this setting, such as time pressures and a lack of familiarity with the patient and therefore difficulty differentiating pain behaviours from the patient's usual behaviour. Relatives and carers are often present in the ED and can provide an understanding of the patient's usual behaviours and therefore allow identification of changes in behaviours related to pain [23-25]. Even so, caution is required when using observational scales and checklists to assess pain severity as the expression of pain behaviours varies between individuals who are experiencing equal levels of pain $[26,27]$. Furthermore, there is evidence to suggest that when a proxy is used to assess pain they tend to under report pain intensity when compared a patient's self-reported pain score, which further complicates pain assessment [28-30].

Without an accurate pain assessment to guide appropriate pain management and to evaluate the efficacy of prescribed interventions, pain may be inadequately managed and patient suffering prolonged. The use of pain assessment tools and their value in guiding pain management is well documented in the literature, however there is limited information regarding the impact of cognitive impairment on pain assessment practices specifically in the ED setting. Therefore, this paper aims to review the current pain assessment practices and how the presence of cognitive impairment influences an elderly patient's pain assessment in the ED when they present with an injury due to a fall.

\section{Methods}

Articles were identified using keyword database searches and then snowballing from the reference lists of the relevant articles identified. The databases EMBASE, ProQuest, PubMed, Science Direct, SciFinder and the Curtin University Library database were searched using the terms 'emergency', 
'emergency department', 'hospital', 'cognitive impairment', 'pain assessment', 'pain assessment methods', 'elderly', and 'frequency of pain assessment'. Searches were limited to peer-reviewed studies and articles that were published in English. If the search yielded an excessive number of results, then the search was restricted to articles published in the last ten years, however, one EMBASE search was limited to articles published within the last year, and another EMBASE search was limited to articles published within the last two years to reduce the number of results to less than 2000. In the three cases where the number of results was still greater than 1000, theme and relevance filters were applied to the results to reduce the number to a more manageable list. The 1033 articles identified in the searches were screened for relevance by title, reducing the list to 102 articles. After removing 23 duplicates, the remaining 79 articles were screened by abstract leaving a final list of 53 articles. Reference lists of these articles were used to identify a further 76 relevant articles. Manual searches added a further five articles to the final list of 134 articles for full-text review. Of these, 26 articles have been included in the review, selected based on their relevance to the aim of this paper (See Figure 1). Reasons for exclusion included lack of relevance, lack of focus on cognitively impaired patients and/or the elderly, wrong setting, lack of originality, poor methodology, and full version of the article was unavailable. One reviewer (JJ) conducted the literature searches to produce the list of 102 articles which was then screened by JH. The articles for full-text review were reviewed by JJ and screened by $\mathrm{JH}$ and TFS to give the final list of articles for inclusion in the review.

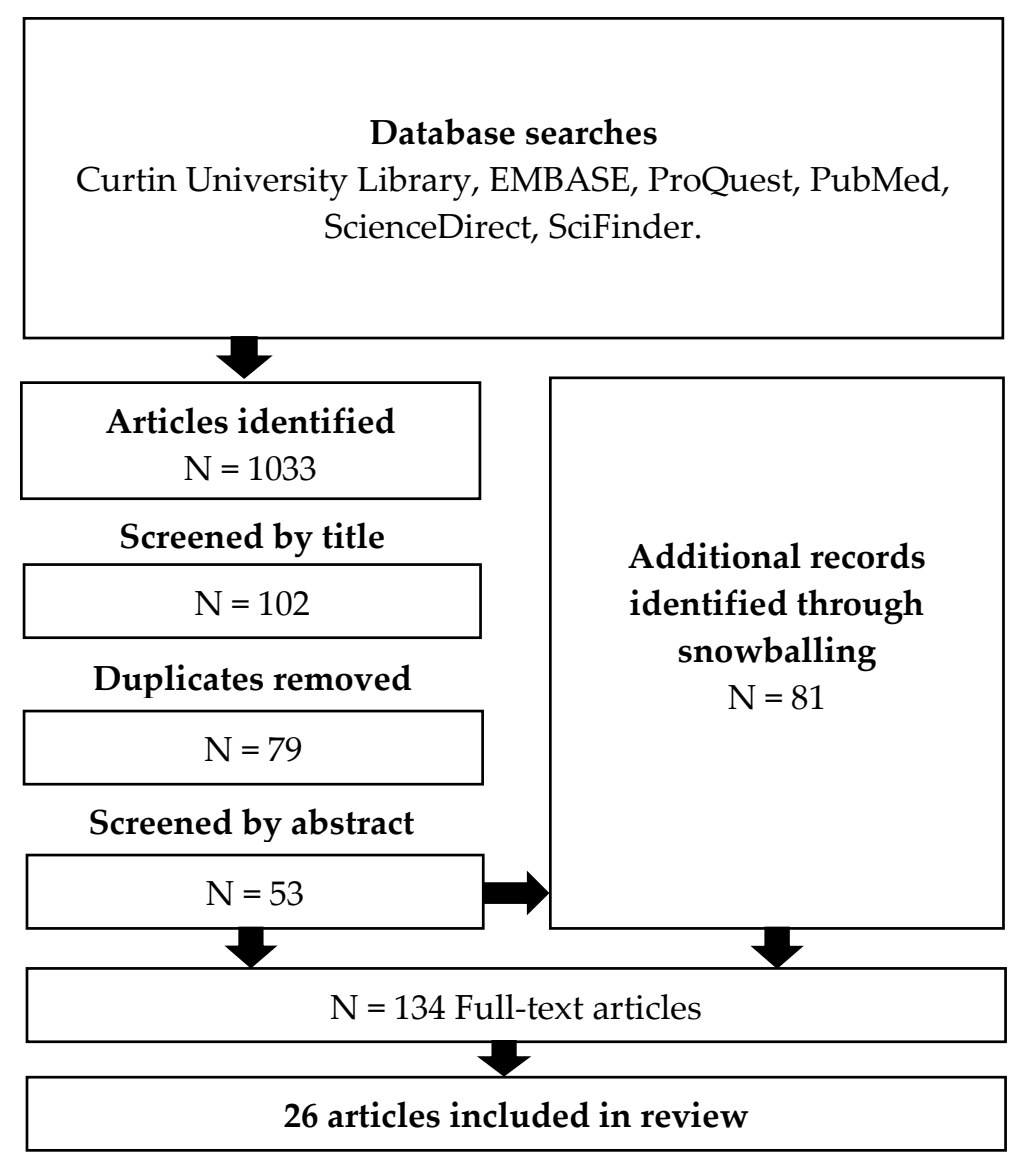

Figure 1. Literature search. Keyword searches of the databases were used to identify articles for potential inclusion in the review. Additional articles were identified through snowballing. 


\section{Findings}

\subsection{Methods of Pain Assessment}

The use of standardised tools to assess pain improves the recognition of pain [31]. In an acute care setting, ideal pain assessment tools are easy to administer, rapid, accurate, valid, reliable, widely applicable to different patient groups, use self-report (if possible), and do not require special equipment or resources [32]. Numerous tools for pain assessment were identified in the literature and these can be categorised into self-report or observational pain assessment tools, as well as unidimensional or multidimensional tools. A systematic review conducted by Lichtner et al. [33] evaluated the psychometric properties and clinical utility of 28 pain assessment tools for use in people with dementia and concluded that while the Abbey Pain Scale, DS-DAT, DOLOPLUS-2, PACSLAC, PAINAD, Mahoney Pain Scale and ECPA have been identified as possible candidates for recommendation for common use, based on current evidence no definitive recommendations can be made.

Recent studies have found that ED staff tend to use visual or verbal analogue scales to assess pain [34-36]. One of these studies reported that there was no evidence that ED staff used pain assessment tools designed specifically for use in cognitively impaired people [34]. Instead, ED nurses tend to resort to their own intuition or observations of changes of physiological parameters, such as respiratory rate, instead of standardised observational pain assessment tools to determine pain levels [35]. This is not ideal as physiological parameters are not able to discriminate pain from other sources of distress and their absence does not reliably exclude the possibility that the individual is in pain $[37,38]$. The studies that were identified in the literature searches only report qualitative data regarding the utilisation of pain assessment tools in the ED for elderly patients with cognitive impairments. Therefore, future studies should attempt to describe pain assessment practices in the ED by quantifying the frequency of use of specific pain assessment tools in this group.

\subsection{Frequency of Pain Assessment}

Regular assessment of pain should be a part of any health care environment and is important for the delivery of quality care in the ED [21,22]. Despite this, studies show that pain is often under-assessed in the ED $[34,36,39,40]$. A study conducted in the United States (US) involving a retrospective review of medical charts of elderly patients with hip fractures in the ED found that whilst most patients had some record or mention of pain on their chart, $34 \%$ of patients' pain was not assessed using a standardised method such as a NRS [40]. Similarly, Australian studies have found that of patients with a fractured neck of femur who present to the ED, between $32 \%$ and $47 \%$ of patients do not have a pain score recorded during their ED admission [34,36]. A summary of selected studies that investigate pain assessment practices in the ED can be found in Table 1. These studies suggest that both in Australia and the UK, pain tends to be under-assessed for elderly patients in the ED.

For patients with a cognitive impairment, the literature suggests that the frequency of pain assessment is likely to be even lower. A study conducted in the United Kingdom found that pain scores are not recorded in the ED for 55\% of cognitively impaired patients compared with $25 \%$ of those cognitively intact [41]. No comparable Australian studies were identified in the literature that investigated the frequency of pain assessment in elderly patients with cognitive impairment in the ED. 
Table 1. Summary of selected studies that investigate pain assessment practices in the ED.

\begin{tabular}{|c|c|c|c|c|}
\hline Authors & Design & Size & Setting & Findings \\
\hline $\begin{array}{l}\text { Fry, Chenoweth, } \\
\text { and Arendts } \\
\text { (2016) [35] }\end{array}$ & $\begin{array}{l}\text { Focus group } \\
\text { interviews, } \\
\text { qualitative }\end{array}$ & $\begin{array}{l}80 \text { emergency } \\
\text { nurses, } 16 \text { focus } \\
\text { groups }\end{array}$ & $\begin{array}{l}\text { Four Australian } \\
\text { EDs }\end{array}$ & $\begin{array}{l}\text { Nurses reported that visual or verbal } \\
\text { analogue scales for pain assessment are } \\
\text { often unsuitable in cognitively impaired } \\
\text { patients. When these methods failed, } \\
\text { nurses relied on clinical judgement and } \\
\text { physiological measures (e.g., respiratory } \\
\text { rate) rather than standardised } \\
\text { observational pain assessment tools. }\end{array}$ \\
\hline $\begin{array}{l}\text { Fry, Arendts, } \\
\text { Chenoweth, and } \\
\text { MacGregor } \\
\text { (2015) [34] }\end{array}$ & $\begin{array}{l}\text { Retrospective } \\
\text { cross-sectional } \\
\text { study of patient ED } \\
\text { records }\end{array}$ & $\begin{array}{l}255 \text { elderly patients } \\
\text { with long bone } \\
\text { fractures }\end{array}$ & $\begin{array}{l}\text { Four Australian } \\
\text { EDs }\end{array}$ & $\begin{array}{l}\text { Only } 68 \% \text { of patients had a pain score } \\
\text { during their ED admission. The verbal } \\
\text { analogue scale was routinely used. There } \\
\text { was no evidence that ED staff used tools } \\
\text { designed specifically for cognitively } \\
\text { impaired people. } \\
204 \text { of } 255 \text { patients received analgesia in the } \\
\text { ED. A cognitively impaired patient was not } \\
\text { more likely to receive no analgesia } \\
\text { compared with a cognitively intact patient. } \\
\text { Median wait time to analgesia was } 72 \text { min } \\
\text { for cognitively intact patients compared } \\
\text { with } 149 \text { min for cognitively impaired } \\
\text { patients. }\end{array}$ \\
\hline $\begin{array}{l}\text { Holdgate, } \\
\text { Shepherd, and } \\
\text { Huckson } \\
\text { (2010) [36] }\end{array}$ & $\begin{array}{l}\text { Retrospective } \\
\text { cross-sectional } \\
\text { study of patient ED } \\
\text { records }\end{array}$ & $\begin{array}{l}646 \text { patients with } \\
\text { fractured neck of } \\
\text { femur }\end{array}$ & $\begin{array}{l}36 \text { EDs across } 5 \\
\text { Australian states }\end{array}$ & $\begin{array}{l}\text { Confusion/dementia was reported as a } \\
\text { barrier to analgesia in } 42 \text { out of the } 99 \\
\text { patients who had a barrier recorded. } \\
47 \% \text { of patients had no documented pain } \\
\text { score during their ED admission. } \\
\text { Visual analogue scales, verbal numerical } \\
\text { pain scores and Likert scales were used. }\end{array}$ \\
\hline $\begin{array}{l}\text { McDermott, } \\
\text { Nichols, and } \\
\text { Lovell (2014) [41] }\end{array}$ & $\begin{array}{l}\text { Retrospective } \\
\text { cross-sectional } \\
\text { study of patient ED } \\
\text { records }\end{array}$ & $\begin{array}{l}224 \text { patients with } \\
\text { fractured neck of } \\
\text { femur }\end{array}$ & $\begin{array}{l}\text { Wythenshawe } \\
\text { Hospital ED, } \\
\text { Manchester, United } \\
\text { Kingdom. }\end{array}$ & $\begin{array}{l}\text { A pain score was documented for } 45 \% \text { of } \\
\text { cognitively impaired patients compared } \\
\text { with } 75 \% \text { of cognitively intact patients. } \\
45 \% \text { of cognitively impaired patients were } \\
\text { not offered an analgesic while only eight } \\
\text { percent of cognitively intact patients had no } \\
\text { prescribed analgesia. }\end{array}$ \\
\hline
\end{tabular}

\subsection{Analgesia is Delayed for Elderly Patients with Cognitive Impairment}

The delay to receiving analgesia when presenting to the ED with a painful condition is greater for elderly patients than for younger patients [36,42-44]. This delay is even greater for elderly patients with a cognitive impairment than for those without [34,45]. An Australian study by Fry et al. [34] found that elderly patients who are cognitively impaired who present to the ED with a long bone fracture waited, on average, $149 \mathrm{~min}$ to receive analgesia compared with just $72 \mathrm{~min}$ for cognitively intact patients. This is despite evidence to suggest that cognitively impaired patients do not perceive less pain than cognitively intact patients $[7,46,47]$. There is also evidence that patients who have a cognitive impairment are less likely to receive opioid analgesics compared to cognitively intact patients. A systematic review by Moschinski et al. [48] reported that eight of the 17 studies included in the review found that people with dementia receive less opioid analgesics than patients without dementia, but not less non-opioid analgesics, possibly due to increased concern about adverse effects such as sedation. Furthermore, when an opioid is prescribed to a person with cognitive impairment to manage pain associated with a hip fracture, it is less likely to be a strong opioid [41]. Improving pain assessment practices in the ED has the potential to reduce this delay and therefore improve pain management and patient outcomes [39].

\subsection{Pain Assessment Improves Pain Management}

The routine use of standardised pain assessment tools in the ED is important as use of such tools has been shown to increase the recognition and treatment of pain [31,49-51]. A cross-sectional study conducted in the US found that for older patients who presented to the ED with a diagnosed painful condition, the odds of receiving a prescription for an analgesic were 1.61 (95\% CI: 1.42 to 1.82 ) if 
a pain score was documented compared with no pain score, and the prescription was more likely to be an opioid [50]. Another US study assessed the influence of the introduction of mandatory verbal numeric pain score assessments on analgesic use for patients presenting to the ED with typically painful conditions [39]. After the introduction of mandatory pain assessments, the number of patients receiving analgesics increased from $25 \%$ to $36 \%(p<0.001)$, and the average wait time to receive analgesia was reduced by $39 \mathrm{~min}(95 \% \mathrm{CI}:-7$ to $84 \mathrm{~min}$ ) [39]. These US studies demonstrate how increased utilisation of pain assessment tools has the potential to improve pain management. No studies were identified in the literature that report on the influence of pain assessment tool utilisation on pain management practices for cognitively impaired older patients in EDs in other countries.

\subsection{Consequences of Poor Pain Management}

Inadequate treatment of pain leads to immediate and delayed negative consequences for the patient. As well as discomfort, immediate consequences of untreated pain include physiological changes such as tachycardia, increased blood pressure, increased myocardial oxygen demand, changes of immune function, hypercoagulability, and metabolic changes [52]. Untreated pain also contributes to behavioural changes in elderly patients. A study conducted by Erel et al. [53] found that behavioural disorders, mainly aggressive behaviour, occurred in about one third of the elderly patients who reported pain as opposed to none of the patients who were pain free. Behavioural disorders were also more likely in patients who were both in pain and cognitively impaired $(36.4 \%)$ than those who were in pain but did not have a cognitive impairment (16.7\%) [53].

\section{Conclusions}

Elderly people are at risk of both injuries due to falls and cognitive impairment and therefore make up a large portion of presentations to the ED. Pain assessment in this patient group can be challenging as cognitive impairment reduces their ability to self-report pain. International studies show that the routine utilisation of standardised pain assessment tools can increase analgesic prescribing and potentially reduce wait time to analgesia in the ED. Studies were identified in the literature that presented data on the pain assessment practices of Australian, UK and US ED staff regarding cognitively impaired elderly patients, however no study could be identified that quantified the frequency of utilisation of specific pain assessment tools. There remains a problem of underutilisation of appropriate pain assessment tools in this patient group in the ED setting, with evidence to suggest that this is leading to suboptimal use of analgesics and poorer control of pain. Health professionals, including pharmacists, can play a role in promoting the regular use of standardised pain assessment tools in their patients to ensure that analgesics are used appropriately and are efficacious. Future studies should attempt to quantify the frequency of utilisation of various pain assessment tools in the ED focusing on elderly patients with cognitive impairments. A better understanding of current pain assessment practices would help to inform improvements in pain assessment and management for this vulnerable patient group.

Acknowledgments: No funding was provided for this project.

Author Contributions: J.H. conceived the project. J.J. undertook the literature review. J.J., T.F.S. and J.H. have all contributed to the writing and review of the manuscript.

Conflicts of Interest: J.H. is one of the originators of the electronic Pain Assessment Tool (ePAT) which is being commercialised by EPAT Technologies Ltd. The other two authors declare no conflict of interest.

\section{References}

1. Registered Nurses' Association of Ontario. Assessment and Management of Pain, 3rd ed.; Registered Nurses' Association of Ontario: Toronto, ON, Canada, 2013.

2. Schofield, P.; O'mahony, S.; Collett, B.; Potter, J. Guidance for the assessment of pain in older adults: A literature review. Br. J. Nurs. 2008, 17, 914-918. [CrossRef] [PubMed] 
3. Brummel-Smith, K.; London, M.R.; Drew, N.; Krulewitch, H.; Singer, C.; Hanson, L. Outcomes of pain in frail older adults with dementia. J. Am. Geriatr. Soc. 2002, 50, 1847-1851. [CrossRef] [PubMed]

4. Lukas, A.; Niederecker, T.; Günther, I.; Mayer, B.; Nikolaus, T. Self- and proxy report for the assessment of pain in patients with and without cognitive impairment. J. Gerontol. Geriatr. 2013, 3, 214-221. [CrossRef] [PubMed]

5. Scherder, E.; Bouma, A. Visual analogue scales for pain assessment in Alzheimer's disease. Gerontology 2000, 46, 47-53. [CrossRef] [PubMed]

6. Wynne, C.F.; Ling, S.M.; Remsburg, R. Comparison of pain assessment instruments in cognitively intact and cognitively impaired nursing home residents. Geriatr. Nurs. 2000, 21, 20-23. [CrossRef] [PubMed]

7. Kunz, M.; Mylius, V.; Scharmann, S.; Schepelman, K.; Lautenbacher, S. Influence of dementia on multiple components of pain. Eur. J. Pain 2009, 13, 317-325. [CrossRef] [PubMed]

8. Vos, T.; Allen, C.; Arora, M.; Barber, R.M.; Bhutta, Z.A.; Brown, A.; Carter, A.; Casey, D.C.; Charlson, F.J.; Chen, A.Z.; et al. Global, regional, and national incidence, prevalence, and years lived with disability for 310 diseases and injuries, 1990-2015: A systematic analysis for the global burden of disease study 2015. Lancet 2016, 388, 1545-1602. [CrossRef]

9. World Health Organization. WHO Global Report on Falls Prevention in Older Age; World Health Organization: Geneva, Switzerland, 2007; pp. 1-9.

10. Burns, E.R.; Stevens, J.A.; Lee, R. The direct costs of fatal and non-fatal falls among older adults-united states. J. Saf. Res. 2016, 58, 99-103. [CrossRef] [PubMed]

11. Stenhagen, M.; Ekström, H.; Nordell, E.; Elmståhl, S. Accidental falls, health-related quality of life and life satisfaction: A prospective study of the general elderly population. Arch. Gerontol. Geriatr. 2014, 58, 95-100. [CrossRef] [PubMed]

12. Bradley, C. Trends in Hospitalisations due to Falls by Older People, Australia 1999-00 to 2010-11 (Injury Research and Statistics Series No. 84. Cat. No. INJCAT 160); Australian Institute of Health and Welfare: Canberra, Australia, 2013. Available online: Http://www.aihw.gov.au/publication-detail/?id=60129543594 (accessed on 5 May 2017).

13. Tomlinson, E.J.; Phillips, N.M.; Mohebbi, M.; Hutchinson, A.M. Risk factors for incident delirium in an acute general medical setting: A retrospective case-control study. J. Clin. Nurs. 2017, 26, 658-667. [CrossRef] [PubMed]

14. Fortini, A.; Morettini, A.; Tavernese, G.; Facchini, S.; Tofani, L.; Pazzi, M. Delirium in elderly patients hospitalized in internal medicine wards. Intern. Emerg. Med. 2014, 9, 435-441. [CrossRef] [PubMed]

15. Morrison, R.; Magaziner, J.; Gilbert, M.; Koval, K.; McLaughlin, M.A.; Orosz, G.; Strauss, E.; Siu, A.L. Relationship between pain and opioid analgesics on the development of delirium following hip fracture. J. Gerontol. A Biol. Sci. Med. Sci. 2003, 58, 76-81. [CrossRef] [PubMed]

16. Finkelstein, E.; Prabhu, M.; Chen, H. Increased prevalence of falls among elderly individuals with mental health and substance abuse conditions. Am. J. Geriatr. Psychiatry 2007, 15, 611-619. [CrossRef] [PubMed]

17. American Psychiatric Association. Diagnostic and Statistical Manual of Mental Disorders: DSM-5, 5th ed.; American Psychiatric Association: Arlington, VA, USA, 2013.

18. Bo, M.; Bonetto, M.; Bottignole, G.; Porrino, P.; Coppo, E.; Tibaldi, M.; Ceci, G.; Raspo, S.; Cappa, G.; Bellelli, G. Length of stay in the emergency department and occurrence of delirium in older medical patients. J. Am. Geriatr. Soc. 2016, 64, 1114-1119. [CrossRef] [PubMed]

19. Gray, L.C.; Peel, N.M.; Costa, A.P.; Burkett, E.; Dey, A.B.; Jonsson, P.V.; Lakhan, P.; Ljunggren, G.; Sjostrand, F.; Swoboda, W.; et al. Profiles of older patients in the emergency department: Findings from the interRAI Multinational Emergency Department Study. Ann. Emerg. Med. 2013, 62, 467-474. [CrossRef] [PubMed]

20. Shah, M.N.; Jones, C.M.C.; Richardson, T.M.; Conwell, Y.; Katz, P.; Schneider, S.M. Prevalence of depression and cognitive impairment in older adult emergency medical services patients. Prehosp. Emerg. Care 2011, 15, 4-11. [CrossRef] [PubMed]

21. Schnitker, L.; Martin-Khan, M.; Burkett, E.; Beattie, E.; Jones, R.; Gray, L. Process quality indicators targeting cognitive impairment to support quality of care for older people with cognitive impairment in emergency departments. Acad. Emerg. Med. 2015, 22, 285-298. [CrossRef] [PubMed]

22. White, C.; Katz, B. Position Statement 21: Pain in Older People. 2012. Available online: http:/ /www.anzsgm. org/documents/PositionStatementNo21PaininOlderPeople_000.pdf (accessed on 5 May 2017). 
23. Fox, P.; Solomon, P.; Raina, P.; Jadad, A.R. Barriers and facilitators in pain management in long-term care institutions: A qualitative study. Can. J. Aging 2004, 23, 269-280. [CrossRef] [PubMed]

24. Schnitker, L.M.; Beattie, E.R.A.; Martin-Khan, M.; Burkett, E.; Gray, L.C. Characteristics of older people with cognitive impairment attending emergency departments: A descriptive study. Australas. Emerg. Nurs. J. 2016, 19, 118-126. [CrossRef] [PubMed]

25. Fry, M.; Chenoweth, L.; MacGregor, C.; Arendts, G. Emergency nurses perceptions of the role of family/carers in caring for cognitively impaired older persons in pain: A descriptive qualitative study. Int. J. Nurs. Stud. 2015, 52, 1323-1331. [CrossRef] [PubMed]

26. Wells, N.; Pasero, C.; McCaffery, M. Improving the quality of care through pain assessment and management. In Patient Safety and Quality: An Evidence-Based Handbook for Nurses; Hughes, R., Ed.; Agency for Healthcare Research and Quality: Rockville, MD, USA, 2008.

27. Pasero, C.; McCaffery, M. No self-report means no pain-intensity rating: Assessing pain in patients who cannot provide a report. Am. J. Nurs. 2005, 105, 50-53. [CrossRef] [PubMed]

28. Pautex, S.; Michon, A.; Guedira, M.; Emond, H.; Lous, P.L.; Samaras, D.; Michel, J.P.; Herrmann, F.; Giannakopoulos, P.; Gold, G. Pain in severe dementia: Self-assessment or observational scales? J. Am. Geriatr. Soc. 2006, 54, 1040-1045. [CrossRef] [PubMed]

29. Van Herk, R.; Van Dijk, M.; Biemold, N.; Tibboel, D.; Baar, F.P.M.; De Wit, R. Assessment of pain: Can caregivers or relatives rate pain in nursing home residents? J. Clin. Nurs. 2009, 18, 2478-2485. [CrossRef] [PubMed]

30. Pierik, J.G.J.; Ijzerman, M.J.; Gaakeer, M.I.; Vollenbroek-Hutten, M.M.R.; Doggen, C.J.M. Painful discrimination in the emergency department: Risk factors for underassessment of patients' pain by nurses. J. Emerg. Nurs. 2017, 43, 228-238. [CrossRef] [PubMed]

31. Kamel, H.K.; Phlavan, M.; Malekgoudarzi, B.; Gogel, P.; Morley, J.E. Utilizing pain assessment scales increases the frequency of diagnosing pain among elderly nursing home residents. J. Pain Symptom Manag. 2001, 21, 450-455. [CrossRef]

32. Jennings, P.A.; Cameron, P.; Bernard, S. Measuring acute pain in the prehospital setting. Emerg. Med. J. 2009, 26, 552-555. [CrossRef] [PubMed]

33. Lichtner, V.; Dowding, D.; Esterhuizen, P.; Closs, S.J.; Long, A.F.; Corbett, A.; Briggs, M. Pain assessment for people with dementia: A systematic review of systematic reviews of pain assessment tools. BMC Geriatr. 2014, 14, 138. [CrossRef] [PubMed]

34. Fry, M.; Arendts, G.; Chenoweth, L.; Macgregor, C. Cognitive impairment is a risk factor for delayed analgesia in older people with long bone fracture: A multicenter exploratory study. Int. Psychogeriatr. 2015, 27, 323-328. [CrossRef] [PubMed]

35. Fry, M.; Chenoweth, L.; Arendts, G. Assessment and management of acute pain in the older person with cognitive impairment: A qualitative study. Int. Emerg. Nurs. 2016, 24, 54-60. [CrossRef] [PubMed]

36. Holdgate, A.; Shepherd, S.A.; Huckson, S. Patterns of analgesia for fractured neck of femur in Australian emergency departments. Emerg. Med. Australas. 2010, 22, 3-8. [CrossRef] [PubMed]

37. Herr, K. Pain in the older adult: An imperative across all health care settings. Pain Manag. Nurs. 2010, 11 (Suppl. 2), S1-S10. [CrossRef] [PubMed]

38. Herr, K.; Coyne, P.J.; Key, T.; Manworren, R.; McCaffery, M.; Merkel, S.; Pelosi-Kelly, J.; Wild, L. Pain assessment in the nonverbal patient: Position statement with clinical practice recommendations. Pain Manag. Nurs. 2006, 7, 44-52. [CrossRef] [PubMed]

39. Nelson, B.P.; Cohen, D.; Lander, O.; Crawford, N.; Viccellio, A.W.; Singer, A.J. Mandated pain scales improve frequency of ED analgesic administration. Am. J. Emerg. Med. 2004, 22, 582-585. [CrossRef] [PubMed]

40. Herr, K.; Titler, M. Acute pain assessment and pharmacological management practices for the older adult with a hip fracture: Review of ED trends. J. Emerg. Nurs. 2009, 35, 312-320. [CrossRef] [PubMed]

41. McDermott, J.H.; Nichols, D.R.; Lovell, M.E. A case-control study examining inconsistencies in pain management following fractured neck of femur: An inferior analgesia for the cognitively impaired. Emerg. Med. J. 2014, 31, e2-e8. [CrossRef] [PubMed]

42. Boccio, E.; Wie, B.; Pasternak, S.; Salvador-Kelly, A.; Ward, M.F.; D'Amore, J. The relationship between patient age and pain management of acute long-bone fracture in the ED. Am. J. Emerg. Med. 2014, 32, 1516-1519. [CrossRef] [PubMed] 
43. Daoust, R.; Paquet, J.; Lavigne, G.; Sanogo, K.; Chauny, J.M. Senior patients with moderate to severe pain wait longer for analgesic medication in EDs. Am. J. Emerg. Med. 2014, 32, 315-319. [CrossRef] [PubMed]

44. Quattromani, E.; Normansell, D.; Storkan, M.; Gerdelman, G.; Krits, S.; Pennix, C.; Sprowls, D.; Armbrecht, E.; Dalawari, P. Oligoanalgesia in blunt geriatric trauma. J. Emerg. Med. 2015, 48, 653-659. [CrossRef] [PubMed]

45. Hwang, U.; Richardson, L.D.; Sonuyi, T.O.; Morrison, R.S. The effect of emergency department crowding on the management of pain in older adults with hip fracture. J. Am. Geriatr. Soc. 2006, 54, 270-275. [CrossRef] [PubMed]

46. Chibnall, J.T.; Tait, R.C. Pain assessment in cognitively impaired and unimpaired older adults: A comparison of four scales. Pain 2001, 92, 173-186. [CrossRef]

47. Feldt, K.S.; Ryden, M.B.; Miles, S. Treatment of pain in cognitively impaired compared with cognitively intact older patients with hip-fracture. J. Am. Geriatr. Soc. 1998, 46, 1079-1085. [CrossRef] [PubMed]

48. Moschinski, K.; Kuske, S.; Andrich, S.; Stephan, A.; Gnass, I.; Sirsch, E.; Icks, A. Drug-based pain management for people with dementia after hip or pelvic fractures: A systematic review. BMC Geriatr. 2017, 17, 1-15. [CrossRef] [PubMed]

49. Fuchs-Lacelle, S.; Hadjistavropoulos, T.; Lix, L. Pain assessment as intervention: A study of older adults with severe dementia. Clin. J. Pain 2008, 24, 697-707. [CrossRef] [PubMed]

50. Iyer, R.G. Pain documentation and predictors of analgesic prescribing for elderly patients during emergency department visits. J. Pain Symptom Manag. 2011, 41, 367-373. [CrossRef] [PubMed]

51. Provost, J.C. Adoption of a pain assessment tool in older homebound patients with dementia in a housecall practice: A dissemination study. Clin. Sch. Rev. 2012, 5, 124-131. [CrossRef]

52. Dunwoody, C.J.; Krenzischek, D.A.; Pasero, C.; Rathmell, J.P.; Polomano, R.C. Assessment, physiological monitoring, and consequences of inadequately treated acute pain. J. Perianesth. Nurs. 2008, 9 (Suppl. 1), 11-27. [CrossRef]

53. Erel, M.; Shapira, Z.; Volicer, L. Behavioral problems of seniors in an emergency department. J. Emerg. Med. 2013, 45, 13-18. [CrossRef] [PubMed]

(C) 2017 by the authors. Licensee MDPI, Basel, Switzerland. This article is an open access article distributed under the terms and conditions of the Creative Commons Attribution (CC BY) license (http:/ / creativecommons.org/licenses/by/4.0/). 